\title{
Enhancing Productivity of Water through Integrated Water Resources Management
}

\author{
M Y Zainudeen
}

\begin{abstract}
Growing population, increased economic activities and improved standards of living create increased competition and conflicts over the limited fresh water resource. A combination of social inequity, economic marginalization and lack of effective poverty alleviation programs also force people living in extreme poverty to over exploit soil and forestry resources, which often results in negative impacts on water resources. Further pollution from domestic, agricultural and industrial waste deteriorate the water quality which influences water usability downstream, threatens human health and the functioning of aquatic ecosystems, leading to poor overall productivity of water. Water scarcity will become more acute over time in the absence of significant efforts to enhance the productivity of water in all water use sectors and maintaining ecological balance and sustainability.
\end{abstract}

The above problems are aggravated by the shortcomings in the management of water. Sectoral approaches to water resources management have dominated all over and are still prevailing in many parts of the world, leading to fragmented and uncoordinated development and management of the source. Thus the overall problem, low productivity of water, is caused by both increased competition for finite resources and inefficient water governance.

Productivity of water is a much spoken topic among the policy makers, investors, and managers in the water resources development sector at International level, but it has not gained much publicity or attention locally, especially among the politicians and water users. Current scenario seeks an environmentally sustainable and socially acceptable policy framework for developing \& managing water resources.

In the event of diminishing availability of fresh water and increasing demand necessitates a new approach for water resources management - Integrated water resources management- which is gaining the attention of the water professionals, policy makers and mangers all over world.

Keywords: Water Resources, Water Management, Integration, Environment, Productivity of Water

\section{Introduction}

Water provides the basis for the existence of living being and maintaining the ecosystem in the globe at the same time it is at the core of both development and environmental problems. The primary reason for environmental problems is the activities of the human in the landscape, either in order to have access to water, food, fodder, fuel-wood, timber, energy, or to dispose sanitary waste, solid waste, and industrial effluents, under the cover of development.

Water sector is in a state of crisis in many developing countries, especially in the arid and semi- arid regions due to pollution, over extraction, lack of allocation \& management polices etc. In most countries almost all the potential water resources have already been developed and consumed without any consideration to the welfare of the future generations. It is true that water is a renewable resource but the realities of renewable phenomena, largely depends on the overall management practices exercised presently on the available water. New sources of water are becoming scarce, more expensive to develop, and require more expertise and technical know how for planning, designing and implementation since the amount of available fresh water is limited in any country on a longterm basis.

Further, natural conditions and human activities have, over the past few decades, affected the quality and quantity of available water. This situation alarms that water can no longer be

Eng. M Y Zainudeen, PGDIP (Eng), M Sc (Eng), C. Eng,, I Eng, FIE(Sri Lanka), MIMSL, Currently working as the Deputy Chief Secretary (Engineering Services) of the North Western Province. 
considered as a cheap resource for use and abuse, without a penalty in the future of mankind.

The entire water world is facing a severe crisis due to the strong, ongoing globalization process, which is very complex by it-self. Further, in spite of this scenario, the ad-hoc and isolated usage practice of water resources has brought this sector into a severe distress. Currently agricultural sector uses a large amount of water, productivity of such use is to be established and justified. The sector will face severe challenges in the future, in the light of diminishing fresh water resources and increasing demand for the same posed by the increasing population associated with improved living standards and urbanization. This will be further aggravated by the demand created by the industrial sector which assures a considerable economic growth in the urban as well as in the rural sector

If this current trend continues, water sector will become a major problem, with serious consequences on health, food production and sustainability of the ecosystem and heavy investment to overcome the problematic situation. Since water is indispensable for life, economic development and ecological balance, water management needs to be viewed with a wider horizon, new dimensions and innovative strategies in an integrated manner, which should be reactive to the current problems and pro-active to take care of the future scenarios, in order to over come the crisis and to ensure sustainability of water sector in the future. New management approaches are required to enhance the productivity of water in all water use sectors through securing water for the needs of the people. This requires an integrated approach for water resources management.

\section{Water in General}

\subsection{Water as a Natural Resource}

Water is a unique natural resource, because of its distinguished characteristics. It is an essential basic resource in every sphere of life of living being. It plays a major role in community needs \& sanitation, agriculture (food production), industry, hydro power generation, recreation \& tourism, protection of nature and so forth. The more important characteristic of water is that it is renewable. In general, the availability of water varies from one locality to another and is dependant on climatic pattern worldwide. It is distributed in the oceans, lakes, and rivers and in the aquifers beneath the surface as blue water and in the soil and plants as green water. Most of the fresh water available for human use is found on or very near to the surface of the land and this is greatly governed by the topography, geology and vegetation cover.

Water is also mobile; it will flow along the slopes under natural conditions. This implies two meanings. One is its mobility over and under the land surface, the other being its ability to move across the man made political/social boundaries, which may have different jurisdiction. Mobility of water across different jurisdiction has created so much of political, decision-making and management problems.

\subsection{Role of Water in Life, Development and Environment}

Life prospers and declines depending on the abundance of water; consequently a variety of life forms have become adapted to varying amount of water. This indicates that each life form, whether plant or animals, has developed tolerance to a certain variability in the amount of water available. In extreme conditions, i.e. during droughts less tolerant species may die out, similarly during floods life may also suffer. Many human activities heavily rely on the supply of water of adequate quality and quantity. Lack of water causes many inconveniences to life, affects the plant growth and ecosystem. Also water has a greater influence on religious and cultural affairs and hence regarded as a spiritual reverence.

Water is also of vital importance to all socioeconomic activities. Much of water withdrawn for economic development activities is eventually returned to the natural system but mostly with contamination, pollution and thermally changed. Further water is an essential commodity for recreation and tourism.

Water, a lubricant, moves through the biosphere driven by solar energy to transport and redistribute the heat. It is a mode of transport for chemicals which are soluble in water, nutrients, pollutants and diseases from one part of the life system to another, thus demonstrating its role \& influence on the lives, environment \& 
ecosystem. Its availability in adequate quantity and quality is indispensable for the efficient functioning of the biosphere.

The overall perception about water, development and environment, among the majority of the developing nations has been very poor in the past, confining only to the extent of meeting their short-term needs. The considerable regard and pervasive feeling about water and environment, that had existed, based on religious and cultural heritage, for ages, got eroded during the last few decades under the increasing pressure of poverty, hunger, mismanagement of natural resources and unplanned development activities. This could have resulted due to political reasons, lack of knowledge \& technology, lack of funding or even due to ignorance. Whatever the reason, this may end up in destruction of development and ecosystem in the long run. Water, environment and development, interact with each other, individually and collectively eternally and hence it is impossible to consider them singly, in isolation. Under natural conditions they are mutually dependent on each other and separation is impossible.

\subsubsection{Perspectives about Water}

Water provides the basis for life, development and environmental problems too. Every one in the society, community or within a defined territory has differing interest and differing perspectives about water. Water user groups, cultural, political, and religious organizations, and NGO's play a considerable role in developing, using and managing water resources. Everyone looks at certain aspects of water resource development \& management, and advocates or promotes ideas corresponding to their interest with certain biasness but the water manager is expected to consider every aspect with an unbiased approach.

In spite of the above, what is of more concern in today's context is the absence of rational and meaningful perspective in the political agenda, about water, in many developing countries. There are many ministries and government agencies to administer and manage the water based development sectors but no agencies exist for establishing and administering water policies (developing, allocating, managing, and protecting). The vulnerability of this resource is least felt by the politicians and the affairs of water sector are going as a "usual business". The effort taken by the water professionals to bring the water business to the political agenda seems to be insufficient and ineffective.

\section{Productive Use of Water}

\subsection{Food Production}

Agriculture remains as the dominant economic factor for many developing countries, in terms of food security, poverty alleviation and employment generation, since majority of their population is in the rural areas. Currently they are mostly engaged in agriculture to feed themselves as well as the urban population. They will continue this exercise in the future too, not only to feed the existing and rapidly increasing rural population, but also to that of urban population. The agricultural sector must not only produce more food for the rising population, but also save water for other uses. This necessitates to, apply water-saving technologies and management practices on one hand and to encourage the communities to introduce new approaches for both rain-fed and irrigated agriculture on the other.

\subsubsection{Blue Water Concept}

Agriculture is said to represent two thirds of all water withdrawals in the world, or twice as much as domestic and industrial needs. This refers only to the water abstracted from blue water (surface water and renewable ground water) reserve (lakes, rivers and aquifers), which is the water flow conventionally considered as an economic resource. Lots of debate is going on the performance of blue water based (irrigated) agriculture in-terms of efficiency, sustainability and economic growth. Lack of focus on the huge amount of green water flow utilized in current food production and providing ecosystem services seems to be simply disregarded.

\subsubsection{Green Water Concept}

Plants do not depend on blue water directly, what happens is roots taking up the soil moisture and releasing to the atmosphere. Soil moisture could be maintained by irrigation and/or precipitation, for a healthy plantation. This involves huge amounts of water, of which 
irrigated (blue water) quantity could usually be assessed but the quantity of green water used remains un-assessed. In other words, rain-fed agriculture plays a vital role in providing the staples for the rural communities in the regions where even irrigation has been in practice for centuries. Thus food (grains, cereals \& meat) production largely depends on the direct use of green water in rain-fed agriculture and livestock.

Furthermore, green water is even more important as the basis for human well being since it sustains biomass in all biomes, which in turn delivers a number of crucial ecosystem services to the society. The most obvious services are food, timber, fodder, renewable fuel and fibers, and less obvious-but not less important-biodiversities.

\subsubsection{Water Use Efficiency and Allocation Policies}

At present, in many developing countries, water is distributed for varying purposes without any formal allocation policy to each sector. About $85 \%$ of the developed water (diverted, stored and extracted from aquifers) is withdrawn for irrigation. This is very huge and needs reconfirmation for its continuity, especially where water resources are scarce. Since irrigation is the largest water use sector, it can also contribute greatly towards water conservation. In many parts of the world it is common that more than half of the water diverted for agriculture does not reach the farm, indicating a higher conveyance loss (from personal experience). Further a large quantity of water is just wasted in the farm due to inappropriate application methods and on farm management practices. This situation promotes not only the wasting of scarce, developed water but also contributes to water logging and salinity, resulting in low productivity. There is a considerable scope for conservation of water by improving conveyance \& application efficiencies in irrigated schemes. Under the circumstances, it is very important for every nation to develop meaningful water allocation policies to maximize the productive use of water.

\subsubsection{Negative impacts of irrigated Agriculture}

The investment in the irrigated agriculture sector has resulted in increased benefits, but productivity response and sustainability of irrigation systems have been constrained by salinity, water logging, low yields, lower prices and poor markets. The use of agro-chemicals and fertilizers, in agricultural and farming activities, have created considerable changes in quality of return water, biodiversity, aquatic ecosystems and change of soil properties, caused by water logging and salinity. These changes include blanket-weed growth and algae blooms in rivers and reservoirs, which are detrimental to human use. Further soil erosion and overexploitation of natural resources are the other adverse effects caused by this sector. Sustainability of food production mainly depends on the sound and efficient water use and conservation practices, primarily in irrigated and rain-fed agriculture, and also in livestock, inland fisheries and agro forestry.

\subsection{Water Supply \& Sanitation}

Although most countries give first priority to satisfy the basic human needs for water, one fifth of the world's population is without safe access to safe drinking water while half of the population lacks adequate sanitation. Safe drinking water supply and environmental sanitation plays a vital role in social upliftment by improving the health conditions and alleviating poverty in our communities and protecting the environment. Clean water must be accessible to each and every one irrespective of their social and economic status and place of living. The water needs of the people living in semi-urban and squatter areas with ultimate poverty should be considered in par with those without poverty for providing access to clean water. The first step to eliminate worse poverty is to eliminate poverty caused by lack of clean water. The water scientists and managers at national, regional and local levels should prioritize this in their agenda for water resources development \& management. Lack of clean water is the main cause for water borne diseases, with dual functions; one is making the people to consume contaminated water and the other being leading to poor sanitation practices, which deteriorate the available water.

\subsubsection{Water Pollution Abatement}

In many cities of developing countries the unprecedented population growth is much 
faster than the city authorities can ever manage to run. It increases pollution growth, destroys their own water resources, while new sources are very remote and may be prohibitive in terms of cost. Also another dilemma is the industries supporting economic growth; generate large quantities of pollution, which increases much faster than the population and the GNP. Already water pollution has enormous dimensions, affecting fresh and ground water sources and the entire ecosystem. Although improved water quality management procedures and technologies are available in the western world, they are not viable in poor countries mainly due to economic reasons. Therefore, abatement of water pollution becomes of fundamental importance requiring a radically improved approach.

\subsubsection{Recycling Process}

The escalating water pollution invites anticipative planning rather than reactive approach to the crisis. In some cases wasted water is seen as a resource for both water and nutrients that could be made use after reclamation and treatment. Reclaimed urban wastewater can be used for agriculture in the urban and peri-urban area; the food produced would be for the farmers as well as for the urban population. The health hazard embodied in this process can be mitigated by simple inexpensive treatment methods. However accumulation of salts in soils and ground water that follows the reuse is a potential threat on long-term usage for irrigation \& other uses.

\subsection{Water for Other Uses}

\subsubsection{Power Generation}

Although hydro power generation does not consume water, it occupies a large land area, covered by the water level of the reservoirs, which may be prohibitive in terms of habitats, forest, wild life and loss of fertile land. Further these will change the climatic and land use pattern in the catchments area causing adverse effects in the future. However, in poor countries, where water resources could be afforded for power generation, seems to be the favourable option against alternative power, at least on short term basis. However, construction of reservoirs for power generation will change the river life and the flow regime in the downstream, causing irreversible damages to the ecosystem and flora fauna.

\subsubsection{Industry}

Industries use water mainly for three purposes, namely, for consuming, cooling, and cleaning. In some industries, major portion of the water abstracted will be consumed or taken away while a little will be discharged in to the natural system, mostly polluted. There are certain types of food processing industries, discharging effluents in to the natural systems, which cannot be permitted, if not treated. The industries, which abstract water for cooling, will discharge a return flow, thermally changed. This may be harmful to some useful microorganisms in the receiving water body and also could alter natural climate of the system.

There are certain other types of industries, which discharge concentrated effluents, harmful to the receiving water body and the environment. Environmental scientists and the law enforcing authorities should pay serious attention to this and take necessary preventive \& regulatory measures, to protect the water resources and the environment.

\subsection{Environmental Protection}

\subsubsection{Environmental Needs}

The exact water requirement for the secured continuity of ecosystems is not known clearly but it is the river flow, which is needed for a healthy ecosystem. Ecosystems are water dependent due to different functions of water in it, namely building matter, nutrient carrier and cooler. Terrestrial ecosystems in the upstream of a basin are important for rainwater infiltration, ground water recharge and river flow regimes. Aquatic ecosystems produce a range of economic benefits such as timber, fuel wood and medicinal plants, and they also provide wild life habitats and spawning grounds. The ecosystems depend on water flows, seasonality and water table fluctuations and have water quality as a fundamental determinant. Human system plays a major role in harnessing all the benefits that could be accrued from these physical systems, paying little or no attention to their sustainability. Land and water resources management must ensure that vital ecosystems are maintained and that adverse effects on other 
natural resources are considered and where possible ameliorated when development and management decisions are made. Under the circumstances, complex nature of fresh water systems demands a holistic and integrated approach rather than a piece-meal approach for management of water as well as the environment.

\subsubsection{Water Quality Monitoring}

The main objective of integrated water management is to incorporate water quality monitoring and management procedures into the water management process so that the sustained maintenance of ecosystems integrity, protection of public health and human resources development could be assured. The effective protection of water resources and ecosystems mainly depends on the capacities of the responsible institutions, available skilled staff and the monitoring networks. Water quality management programs require a certain minimum infrastructure, equipment and staff to monitor, analyze, identify and to implement appropriate solutions and to enforce regulatory measures. On the other hand, sustained operation and maintenance of the facilities established for water quality monitoring faces many constraints, due to the continuous monitoring exercises involved and the availability of physical and financial resources.

\section{Water Management}

\subsection{Traditional Water Management}

Traditionally water has been managed on supply-oriented basis to satisfy everyone, without paying sufficient attention to options for influencing water demand and increasing water use efficiency. This has evolved through many an era with different objectives, starting from increased food production, employment generation, then equity and reliability of supply, poverty alleviation and then productivity of water, economic growth and so on. It is true that these objectives have been realized to a certain extent, but with a very low water use efficiency and some irreversible negative impacts too, and creating a situation, in which the water management profession and the society at a large are facing a challenge, the magnitude and complexity of which no earlier generation has had to face. The conventional setup of sectoral water management practices is hardly capable of coping up with the current water problems, which demand an integrated approach to water, land use and ecosystems on the one hand, and address the role of water for social and economical development on the other.

Another major obstacle to effective water management is fragmentation and overlapping of the responsibilities among a large number of agencies involved in the exploitation, allocation, regulation and use of water resource. This fragmentation has to be avoided if better results are expected from water management sector and that could be achieved through effective communication and closer cooperation among concerned ministries, departments and agencies.

\subsection{Integrated Approach for Water Management}

Though adequate and good quality water provides the basis for life, the extent to which the water resource development supports the economic growth and social welfare with improved living conditions is not much understood by many. Reaching a secure situation by satisfying water security, food security and environmental security, demands an integrated approach with proper coordination and certain degree of consensus building. The conventional way has been participation, but experience shows that the civil society may behave in two opposite ways, in harmony or in protest. However, this situation demands a holistic approach to consider fresh water as a finite and vulnerable resource and to integrate the sectoral water plans and programs within the framework of national economic and social policy, for sustainable development. Thus integration can be considered under two basic categories.

- The natural system, with its critical importance for resource availability and quality and

- The human system, which fundamentally is responsible for resource use, waste production \& pollution of the source

Integration has to occur both within and between these categories, considering the variability in time and space. 


\subsubsection{Natural System Integration}

Natural system has a large number of components which actively involve in the affairs taking place in it. Basin is the natural territory and hydrology is the natural science dealing with the dynamics and behavior of water in it, which is the integrated natural unit. In most countries the approach for water management is based on administrative and planning systems in terms of regions, districts, municipalities and usage units (projects), which have a geographical configuration that rarely corresponds to the natural resource units. Social harmony greatly depends on the division of landscape, which is fully governed by the natural laws and sciences. Therefore it creates a shift in thinking towards reviewing the existing administrative and planning systems in order to address the issues merged from the growing pressure on water. Therefore, most appropriate geographical entity for integrated water management, including the integration of land and water-related aspects, appear to be the basin or sub-basin. This is true both for basins within a country and for trans-boundary basins.

Within the natural system, integration has to take place between land and water management, "Green and Blue Water", surface water and ground water management, quality and quantity of water management and upstream and down stream water related interests.

\subsubsection{Human System Integration}

Successful natural system integration depends largely on successful involvement of the human system integration, a rather difficult system to optimize. All aspects of integration require an understanding of the natural system, its capacity, vulnerability and limits. Such integration is inevitably a complex task and perfect integration is rarely achievable. It involves

- Government, dealing with political, financial, legislative and regulative issues

- Private sector - facilitating technological, production and consumption choices based on real value of water and the need to sustain the natural resource base and

- Water users, stakeholders and the civil society adhering to good water governance
Integrative measures are required at all levels from the individual to household to international markets.

On the one hand there are primary stakeholders, like polluters, user associations, authorities and local NGOs. On the other, there are groups whose welfare is influenced or at stake by water resource management decisions. Stakeholder involvement is critical in achieving social acceptance of the outcome. There has to be rules for the participation process to secure legitimacy of viewpoints and legal recognition. Water managers have to help in situation to analyze, and provide easily understandable explanations. Successful cross-sectoral dialogues also depend on access to terminology that bridges the understanding gaps, and on the development of an easily understandable metalanguage.

\subsection{Policy Development}

Prioritizing and optimizing the water based development sectors are necessary in order to achieve the desired economic growth, improved living condition, poverty alleviation and conservation of resource bases and environment. It is imperative to increase the status of water in society and among politicians and policy makers. Politicians, with their interest in the "re-election ambition" are prisoners of their voters and thus can best be reached through the latter. This necessitates conducting public awareness programs with regard to the real situation of the water related development sectors, in order to create adequate understanding. Water resources must become part of the political agenda and be integrated with national economic policy as well as with national sectoral policies. Conversely economic and social policies need to recognize the implications of the water resource policies as well. In pursuing integrated water resources management social, economical and natural conditions need to be recognized.

- Equity - the basic right for all people to have access to water of adequate quantity and quality for the sustenance of human well being.

- Economic efficiency of water use Because of the increasing scarcity of water and financial resources, the finite and vulnerable nature of 
water as a source, and the increasing demand upon it, water must be used with optimum efficiency and productivity.

- Environmental and Ecological Sustainability - Present use of the resource should be managed in a way that does not undermine the life support system thereby compromising use by future generation of the same source.

\subsection{Institutional Development}

Properly designed and constituted institutional arrangement is vital for successful implementation of policy decisions. The main responsibilities of the institutions are to ensure independent and unbiased approach in planning, development, allocation, conservation and management of the resource, including protection of environment and ecosystems ensuring proper distribution, management and monitoring. Involving the public in decisionmaking process, implementing, controlling and management of the system is another important step towards effective water governance. This should be helpful in developing the most appropriate institutional arrangement, capacity building and streamlining the management processes.

\subsection{Economics of Water Resource Development}

The increasing scarcity of good quality water in many developing countries, combined with higher demands from municipal, industrial and agricultural users, is making it increasingly important that the governments introduce measures to recover a large proportion of fixed and recurrent costs in water resource development projects. The users will realize the actual cost of exploitation, development and distribution only when it is transferred to them. More attention should be given to the economic efficiency of water development projects, greater reliance on water pricing, mobilization of resources of private sector and communities. Economic efficiency of projects could be improved by rehabilitating the defective system, minimizing the wastage and unaccounted-for water, recycling and reusing wasted water and improving operation and maintenance. This approach may be more effective in many cases than funding for new projects.
Further a much needed action is to create awareness among the water users (Irrigation, domestic, industry etc.) on the current status of this sector, economic aspects of water resources development, scarcity for capital, diminishing nature of freshwater resources, adverse consequences of wasting developed water and more than anything the cost of not having water when it is needed. This needs to be fostered by the government organizations, non government organizations, civil society, private sector and even the religious organizations. Water crisis must be given equal publicity as that for an energy crisis.

\section{Conclusions}

The main challenges faced by most of the countries struggling for economic and social development are related to water. Water shortages, poor access to clean water, water quality deterioration and environmental degradation and flood impacts are the major threats which require attention and actions through an integrated approach.

There exist a strong link between water resources and agriculture, forestry, torrential and aquatic ecosystems and urban development. Present life style changes and aspirations, including significant increases in the standard of living and per capita income, continued population growth, industrial development, agricultural trends and increased urbanization - all demand higher water consumption in the decades to come. This requires a greater focus on water resources planning issues and to adopt sustainable development, production and consumption patterns through an integrated process in order to fulfill all the water needs. This is the holistic approach required to enhance the productivity of water. Also this approach should ensure that safe water quality standards are maintained and the environment is protected. Integrated approach need to be practiced even in the areas where water resources are in abundance, in order to minimize the threats to the health and to enhance overall productivity of water.

Integration has two main aspects, natural system integration and human system integration. In water sector planning, very often, facts related to the natural system (basin or 
catchment) and their behavior including that of water (hydrological aspects) are not given due prominence; their basic importance is overlooked. Water resources come from systems which include rivers, lakes, wetlands and aquifers. Their planning and management must therefore be considered in association with their functions in the hydrologic cycle and their interactions with physical, chemical and biological processes in terrestrial ecosystems. Therefore most appropriate geographical entity for integrated water management, including the integration of land and water-related aspects appear to be the basin or sub-basin as the natural system.

Success of natural system integration depends largely on successful \& effective involvement of the human system integration, a rather difficult system to optimize. Voices of the civil society and stakeholders; especially the affected groups, must be heard by the Government officials (policy makers) and water managers so that a full cross section of the scenario is disclosed. Therefore it is very vital to integrate the human system (Government, private sector, civil society, water users and stakeholders) in to one common forum in a given natural system for better results.

Integration should pay due attention on equity issues, efficient use of water resources and sustainability of environment and ecosystem. In most water resources development activities, too often, the immediate economic and social benefits are given higher prominence without giving sufficient emphasize on their interrelated adverse impacts on other sectors and ecosystems in the long run. This necessitates integration to follow multi disciplinary and multi sectoral approach to incorporate all possible benefits as well as adverse effects. Therefore integration needs to consider, coordinate and monitor development, usage and ecosystem activities in a single domain, closely in order to ensure that the development is protective, productive $\&$ sustainable.

Integration is greatly influenced and affected by the policies adopted; willingness of the society to change \& embrace integrated process and the readiness to practice new methods. Therefore creating awareness on the importance of integrated water resources management among the policy makers, water users \& stakeholders, private sector and NGOs is of very vital, for better results. Also they need to be enlightened with the economic aspects of water resources development as well.

The success of the efforts taken through integration mainly depends on

(a) Continued satisfactory performance of development systems which deliver the desired benefits at least during the designed period leading towards prosperity and

(b) The systems generate minimum or no adverse effects on the ecosystem, environment and on the related sectors.

The ultimate goals of integrated water resources management are to realize prosperity and happiness among the people through improved economic \& social development resulting from enhanced food security conditions, improved water security \& health conditions, reduced poverty, and sustained and lively ecosystem. This status reflects good water governance and enhanced productivity of water in a given community/territory/nation/country.

\section{References:}

1. Asano, $\mathrm{T}$ (2001), "Water from Water, Closing the cycle", Stockholm Water Front, Swedish International Water Institute, Stockholm.

2. Biswas, A K et el, "Water for Sustainable Development in the 21st century", Water Resource Management Series, Oxford Press

3. Global Water Partnership (2000), "Integrated Water Resources Management, TAC Background Paper No 4, Stockholm, Sweden

4. Hagebro, C et el, (2001), "People and Water Ethics and Goals in the light of Sustainability", Stockholm Water Front, SIWI.

5. Proceedings of "Stockholm Water Symposium", (2001), Swedish International Water Institute, Stockholm

6. United Nations (1996), Integrated Water Resources Management in Asia and the Pacific, Water Resources Series No 75, New York

7. Unlocking the Water Potential for Agriculture, 2003, FAO, Rome

8. Water Resources council \& Secretariat (2000), "National Water Resources Policy and Institutional Arrangements", Colombo, Sri Lanka

9. Young, G J et el, "Global Water Resource Issues", Cambridge University Press

10. Zainudeen, M Y (2001), Water Resources Engineering and Management for Rural 
Communities, the Challenges for Agriculture, and other Water Users in Sri Lanka In the 21st Century, "Engineer" IESL, Colombo.

11. Zainudeen, M Y (2005), Strategies to Address the National Food Security and Environmental Sustainability In The Context Of Changing Climate And Global Trade Rules. "Engineer" IESL, Colombo.

12. Zainudeen, M Y (2007), Water Resources Development/Management for Agriculture in Sri Lanka; Past and Future. "Engineer" IESL, Colombo. 